Short paper and poster abstracts: $38^{\text {th }}$ Congress of the South African Society of Animal Science

\title{
Effect of dietary energy level on efficiency of SA Mutton Merino lambs and Boer goat kids under feedlot conditions
}

\author{
R. Sheridan, A.V. Ferreira, L.C. Hoffman and S.J. Schoeman \\ Dept of Animal Sciences, University of Stellenbosch, P Bag X1, Matieland, 7602, South Africa
}

\section{Introduction}

The potential of the Boer goat as a meat-producing animal has been recognised throughout South Africa (Casey, 1983). In general, the poorer growth rate of goats in comparison to sheep may be due to the fact that their nutrient requirements differ and goats are traditionally reared on diets formulated for sheep. A second explanation might also be attributed to the extra activity of the goat, which increases energy expenditure and lowers feed intake (Naudé \& Hofmeyr, 1980). The Boer goat also grazes and browses a different spectrum of plants than sheep, and has adapted to survive under extensive conditions in dryer areas of South Africa. It also appears that the Boer goat can survive with less water than most sheep breeds. Due to species and environmental differences, the weaning age and weight of Boer goats differs from that of SA Mutton merinos. The Boer goats were 135 days old and the SA Mutton merinos 90 days old at the start of this experiment. This represents the actual weaning age of the animals, as well as the age in which they would normally enter a commercial feedlot. The economy of a feedlot requires that animals be slaughtered at a targeted weight or after a certain amount of days in the feedlot. In this experiment, this duration was 56 days. This study was conducted to determine the influence of dietary energy levels on the feed and water intake and growth parameters of the Boer goat kid in comparison to that of South African Mutton merino lambs. The animals were kept under intensive feeding and management conditions, similar to what would be found in a commercial system.

\section{Materials and Methods}

Sixteen weaned Boer goat (BG) kids and 16 weaned South African Mutton merino (MM) lambs (all castrated) were used for this study. The average initial body weight of the BG kids and MM lambs were $26.23 \pm$ $3.86 \mathrm{~kg}$ and $32.72 \pm 2.13 \mathrm{~kg}$ respectively. The 16 goats or lambs were randomly allocated to two groups of eight. Two pelleted diets were formulated on an isonitrogenous and isomineral basis to contain a low (LE; 8.93 MJ $\mathrm{ME} / \mathrm{kg} \mathrm{DM}$ ) or a high (HE; $10.86 \mathrm{MJ} \mathrm{ME} / \mathrm{kg} \mathrm{DM}$ ) metabolisable energy level. The animals were individually housed and fed ad libitum for 56 days. The animals were given $8 l$ of water daily. Weekly water intake was corrected for evaporation losses by measuring losses from a trough similar to those provided for the animals. Analyses of variance were performed on all the variables measured using the General Linear Models (GLM) procedure of SAS (1990). The differences between the diets and species were, where appropriate, tested separately by means of the null hypotheses $\left(\mathrm{H}_{0}\right)$, with $\mathrm{H}_{0}: \mu=\mu_{0}$ and the alternate hypothesis $\left(\mathrm{H}_{\mathrm{a}}\right)$ being $\mathrm{H}_{\mathrm{a}}: \mu \neq \mu_{0}$. This was done by means of contrast analyses and estimated least square means ( \pm std error) as reported in Table 1 . Differences between the variables were accepted as being significant if the probability of rejection of $\mathrm{H}_{0}$ was less than $5 \%(\mathrm{P}<0.05)$ for diet or species.

\section{Results and Discussion}

The ADG of the Boer goat (Table 1) on the low-energy diet (LEBG) $(0.152 \mathrm{~kg} / \mathrm{day})$ was similar to the ADG of the Boer goat on the high-energy diet (HEBG) $(0.162 \mathrm{~kg} /$ day $)$. However, both were lower $(\mathrm{P}<0.01)$ than the ADG of the MM on both the high-energy diet (HEMM) $(0.281 \mathrm{~kg} /$ day) and the low-energy diet (LEMM) $(0.203 \mathrm{~kg} /$ day $)$. The ADG of the HEMM was also higher $(\mathrm{P}<0.01)$ than that of the LEMM. The cold-carcass weight gave same results. It can also be seen that there was no difference between cumulative feed intakes within species. The sheep had a higher $(\mathrm{P}<0.01)$ intake of feed than the goats. In terms of feed conversion efficiency (FCE), there were no significant differences within diets, but the FCE of HEMM (6.471) and HEBG (7.328) was significantly lower than that of LEMM (9.401) and LEBG (9.089). The cumulative water intake of the LEMM (275.395 $l$ ) and HEMM (264.459 $l$ ) did not differ significantly from one another, but were significantly higher than both the intake of the LEBG $(136.706 l)$ and HEBG $(110.420 l)$. The cumulative water intake of HEBG was significantly lower than that of the LEBG. The water efficiency (water intake per kg weight gain) of the HEMM (17.047) and LEBG (16.441) was similar, but was significantly higher than that of the HEBG (12.605) and significantly lower than that of the LEMM (24.432). In terms of water consumption (water intake per $\mathrm{kg}$ feed intake), there was no significant differences within species, but the BG consumed less $(P<0.01)$ water than the 
Short paper and poster abstracts: $38^{\text {th }}$ Congress of the South African Society of Animal Science

MM. The dressing percentage of the two groups on the low-energy diet, i.e. LEMM (45.610\%) and LEBG (44.528 \%), did not differ significantly from one another. However, both the HEMM $(50.137 \%)$ and HEBG $(47.854 \%)$ had a significantly higher dressing percentage than the LEMM and LEBG. The HEMM's dressing percentage was once again significantly higher $(\mathrm{P}<0.01)$ than that of the HEBG.

Table 1 Growth parameters, carcass yield and feed and water intake of the SA Mutton merino lambs and Boer goat kids (average \pm s.e.).

\begin{tabular}{|c|c|c|c|c|}
\hline & $\begin{array}{l}\mathrm{LEMM}^{1} \\
(\mathrm{n}=8)\end{array}$ & $\begin{array}{l}\mathrm{LEBG}^{1} \\
(\mathrm{n}=8)\end{array}$ & $\begin{array}{l}\mathrm{HEMM}^{2} \\
(\mathrm{n}=8)\end{array}$ & $\begin{array}{l}\mathrm{HEBG}^{2} \\
(\mathrm{n}=7)\end{array}$ \\
\hline \multirow[t]{2}{*}{ Initial body weight (kg) } & $32.125^{\mathrm{a}}$ & $25.750^{b}$ & $33.313^{\mathrm{a}}$ & $26.714^{b}$ \\
\hline & \pm 1.113 & \pm 1.113 & \pm 1.113 & \pm 1.190 \\
\hline \multirow[t]{2}{*}{ Final body weight (kg) } & $43.510^{b}$ & $34.268^{\mathrm{c}}$ & $49.050^{\mathrm{a}}$ & $35.793^{c}$ \\
\hline & \pm 1.405 & \pm 1.405 & \pm 1.405 & \pm 1.502 \\
\hline \multirow[t]{2}{*}{ Body weight gain (kg) } & $11.385^{\mathrm{b}}$ & $8.518^{\mathrm{c}}$ & $15.738^{\mathrm{a}}$ & $9.079^{c}$ \\
\hline & \pm 0.773 & \pm 0.773 & \pm 0.773 & \pm 0.826 \\
\hline \multirow[t]{2}{*}{ ADG (kg/day) } & $0.203^{\mathrm{b}}$ & $0.152^{c}$ & $0.281^{\mathrm{a}}$ & $0.162^{c}$ \\
\hline & \pm 0.014 & \pm 0.014 & \pm 0.014 & \pm 0.015 \\
\hline \multirow[t]{2}{*}{ Cumulative feed intake $(\mathrm{kg})$} & $106.000^{\mathrm{a}}$ & $75.346^{\mathrm{b}}$ & $99.835^{\mathrm{a}}$ & $65.181^{b}$ \\
\hline & \pm 3.975 & \pm 3.975 & \pm 3.975 & \pm 4.250 \\
\hline \multirow[t]{2}{*}{ Cumulative water intake $(l)$} & $275.395^{\mathrm{a}}$ & $136.706^{\mathrm{b}}$ & $264.459^{\mathrm{a}}$ & $110.420^{\mathrm{C}}$ \\
\hline & \pm 7.792 & \pm 7.792 & \pm 7.792 & \pm 8.330 \\
\hline \multirow{2}{*}{$\begin{array}{l}\text { Feed conversion efficiency } \\
\text { (kg feed/kg weight gain) }\end{array}$} & $9.401^{\mathrm{a}}$ & $9.089^{\mathrm{a}}$ & $6.471^{\mathrm{b}}$ & $7.328^{\mathrm{b}}$ \\
\hline & \pm 0.458 & \pm 0.458 & \pm 0.458 & \pm 0.490 \\
\hline \multirow{2}{*}{$\begin{array}{l}\text { Water efficiency } \\
(l \text { water } / \mathrm{kg} \text { weight gain })\end{array}$} & $24.432^{\mathrm{a}}$ & $16.441^{\mathrm{b}}$ & $17.047^{\mathrm{b}}$ & $12.605^{\mathrm{c}}$ \\
\hline & \pm 0.853 & \pm 0.853 & \pm 0.853 & \pm 0.912 \\
\hline \multirow{3}{*}{ Water consumption } & $2.634^{\mathrm{a}}$ & $1.825^{\mathrm{b}}$ & $2.643^{\mathrm{a}}$ & $1.713^{\mathrm{b}}$ \\
\hline & \pm 0.079 & \pm 0.079 & \pm 0.079 & \pm 0.085 \\
\hline & $19.850^{\mathrm{b}}$ & $15.255^{\mathrm{c}}$ & $24.578^{\mathrm{a}}$ & $17.125^{\mathrm{c}}$ \\
\hline Cold carcass mass (kg) & \pm 0.682 & \pm 0.682 & \pm 0.682 & \pm 0.729 \\
\hline \multirow[t]{2}{*}{ Dressing percentage $(\%)$} & $45.610^{c}$ & $44.528^{c}$ & $50.137^{\mathrm{a}}$ & $47.854^{\mathrm{b}}$ \\
\hline & \pm 0.586 & \pm 0.586 & \pm 0.586 & \pm 0.627 \\
\hline
\end{tabular}

\section{Conclusion}

The data obtained in this experiment confirms that SA Mutton merino lambs perform better in feedlot situations than Boer goat kids, especially when fed a high-energy diet. Except for dressing percentage and the water parameters, there were no significant differences between the performance of the Boer goats on a high-energy diet and those on a low-energy diet. This may be the result of the fact that, unlike SA Mutton merinos, Boer goats have always been selected for extensive veld conditions in the past. It is, however, possible that the Boer goats on the high-energy diet stored the excess energy as fat, which may also partly explain their higher dressing percentage. It is also interesting to note that, within diets, there were no statistical differences between the feed conversion efficiencies of the Mutton merino and the Boer goat, although the latter had a lower ADG, which suggests that the Boer goat might also be suitable for intensive feeding.

\section{References}

Casey,N.H., 1983. Bokvleis het $\mathrm{n}$ onbekende waarde. SA Vleishandel 2,4.

Naude,R.T. \& Hofmeyr, H.S., 1980. Meat production In: Goat Production, Ed. Gall, C. Academic Press, London pp. 291-298.

SAS, 1990. SAS/STAT User's Guide Version 6 (4th edition). SAS Inc, Cary. 